\title{
Graduação antecipada do curso de medicina durante a pandemia de COVID-19: avaliação preliminar
}

\author{
Early medical school graduation during the COVID-19 pandemic: preliminary assessment
}

\author{
Paula Adamo de Almeida' (1) paulinha_adamo@hotmail.com \\ Viktoria Weihermann' ${ }^{1}$ (D) vikweihermann@gmail.com \\ Gustavo Lenci Marques ${ }^{1,2}$ (D) gustavolencimarques@gmail.com \\ Camila Girardi Fachin' (D) camilafachin@gmail.com \\ Ipojucan Calixto Fraiz' (D) fraiz@uol.com.br

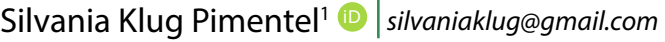

\begin{abstract}
RESUMO
Introdução: O atual surto do novo coronavírus ou Sars-CoV-2, causador da Covid-19, foi relatado pela primeira vez à Organização Mundial da Saúde, pela China, em 31 de dezembro de 2019, sendo declarada pandemia em 11 de março de 2020. Quanto ao espectro clínico da infecção pelo Sars-CoV-2, ele é amplo, variando de quadro assintomático, doença leve do trato respiratório superior, a pneumonia viral grave com insuficiência respiratória e morte. Com uma chance de apresentação clínica grave próxima a 25\%, a infecção pelo Sars-CoV-2 pode levar à sobrecarga dos serviços de saúde e aumentar a demanda tanto por recursos materiais como humanos. Para aumentar a disponibilidade de profissionais da área da saúde envolvidos diretamente no atendimento durante a pandemia, o Ministério da Educação autorizou a antecipação da formatura para estudantes de várias áreas da saúde, incluindo Medicina.
\end{abstract}

Objetivo: O objetivo do presente artigo é realizar uma avaliação preliminar do impacto da antecipação da graduação para os formandos de Medicina durante a pandemia de Covid-19.

Método: Trata-se de estudo observacional e transversal realizado por meio da aplicação de questionário com 13 perguntas: em cinco, utilizou-se escala Likert de avaliação; em seis, adotou-se o formato de múltipla escolha; e duas foram descritivas. O questionário foi enviado, via Formulário Google, a alunos de Medicina das universidades de Curitiba, no Paraná, formados no primeiro semestre de 2020, que anteciparam a outorga de grau em razão da pandemia de Covid-19.

Resultados: Responderam ao questionário 113 formandos, dos quais 101 relataram que já atuam como médicos. Destes, 63,36\% afirmaram que estão trabalhando diretamente no atendimento de casos de Covid-19. Sobre a importância da antecipação da outorga de grau, a maioria dos participantes concorda totalmente ou concorda, e apenas três participantes discordam totalmente. Mais da metade dos entrevistados não se sentem prejudicados com a antecipação da outorga de grau. Contudo, 43,3\% acreditam que deixaram de adquirir informações importantes em sua formação. Por fim, quanto ao fato de trabalharem na pandemia, 79,6\% consideram importante a atuação de médicos recém-formados no combate à Covid-19.

Conclusão: Este estudo mostra que, a princípio, os esforços para a antecipação de formatura foram bem-sucedidos, já que os novos médicos estão contribuindo para aliviar a pressão imposta pela falta de profissionais e promover um melhor cuidado aos pacientes durante a pandemia.

Palavras-chave: Covid-19; Coronavírus; Estudantes de Medicina; Médicos; Pandemia.

\section{ABSTRACT}

Introduction: The current outbreak of the new coronavirus or SARS-CoV-2, which causes COVID-19, was first reported to the World Health Organization on December 31, 2019, being declared a pandemic on March 11, 2020. As for the clinical spectrum of SARS-CoV-2 infection, it is a broad one, ranging from asymptomatic, mild upper respiratory tract disease to severe viral pneumonia with respiratory failure and death. With a chance of severe clinical presentation close to 25\%, SARS-CoV-2 infection can lead to health service overload and increase the demand for material and human resources. Aiming to increase the availability of health professionals directly involved in care during the pandemic, the Ministry of Education authorized the early graduation for students pursuing careers in health, including medicine.

Objective: The aim of this article is to obtain preliminary results of the impact of early graduation for medical students during the COVID-19 pandemic

Method: Observational and cross-sectional study, carried out by applying a questionnaire with 13 questions, five of which used a Likert scale of assessment, six in multiple choice format and two descriptive, via Google Forms, applied to medical students from the universities of Curitiba-PR that graduated earlier in mid-year 2020, due to the COVID-19 pandemic.

Results: 113 recently graduated students answered the questionnaire. 101 participants reported that they are working as physicians and, among them, $63.36 \%$ stated that they are working directly in the treatment of COVID-19 cases. Regarding the importance of an early graduation, most participants fully agree or agree, while only three participants totally disagree. More than half of the interviewees do not feel harmed by the early graduation. However, $43.3 \%$ believe they have failed to acquire important information for their training. Finally, regarding their performance in the pandemic, $79.6 \%$ consider important their role in the fight against COVID-19 pandemic.

Conclusion: The study shows that, at first, the efforts to give the Class of 2020 an early graduation were successful, since these new physicians are contributing to alleviate workforce shortages and provide better care for patients during the pandemic.

Keywords: COVID-19; Coronavirus; Medical Students; Physicians; Pandemic.

1 Universidade Federal do Paraná, Curitiba, Paraná, Brasil.

2 Pontifícia Universidade Católica do Paraná, Curitiba, Paraná, Brasil.

Editora-chefe: Rosiane Viana Zuza Diniz $\quad$ Editor associado: Pedro Tadao Hamamoto Filho

Recebido em 16/12/20; Aceito em 08/03/21. | Avaliado pelo processo de double blind review. 


\section{INTRODUÇÃO}

Nos últimos 20 anos, foram registradas várias epidemias virais, como a do coronavírus da síndrome respiratória aguda grave (Severe Acute Respiratory Syndrome Coronavirus - SarsCoV) em 2002 e 2003, e a influenza H1N1 em 2009'. O atual surto do novo coronavírus ou Sars-CoV-2, causador da coronavirus disease 2019 (Covid-19), foi relatado pela primeira vez à Organização Mundial da Saúde (OMS), pela China, em 31 de dezembro de 2019². Em 30 de janeiro de 2020, o Comitê de Emergência da OMS, por sua vez, declarou a doença uma emergência de saúde global. Pouco tempo depois, em 11 de março, o número de casos de Covid-19 fora da China já havia aumentado 13 vezes e o número de países envolvidos triplicado, levando a OMS a declarar estado de pandemia mundial' .

Quanto ao espectro clínico da infecção pelo Sars-CoV-2, ele é amplo, variando de quadro assintomático, doença de trato respiratório superior leve, a pneumonia viral grave com insuficiência respiratória e morte ${ }^{3}$. Tian et al. ${ }^{4}$, em fevereiro de 2020, descreveram que a proporção de casos graves para casos leves da infecção por Sars-CoV-2 foi aproximadamente 1:4. Uma metanálise realizada por Wang et al. ${ }^{5}$, em março de 2020, demonstrou que a presença de comorbidades aumenta o risco de morte em pacientes com Covid-19. A presença de doença pulmonar obstrutiva crônica (DPOC), por exemplo, está associada a um risco aumentado de quadro grave, além de hipertensão, diabetes, doença cardiovascular e cerebrovascular, e indivíduos idosos ${ }^{3,5}$.

Com uma chance de apresentação clínica grave próxima a $25 \%$, a infecção pelo Sars-CoV-2 pode levar à sobrecarga dos serviços de saúde e aumentar a demanda tanto por recursos materiais como humanos. Por ser uma doença de alta transmissibilidade e pelo fato de os profissionais da área da saúde estarem mais expostos a ela, eles são acometidos com maior frequência e, por isso, necessitam de afastamento para tratamento e recuperação. Tal fato pode levar à falta de profissionais para atendimento em linha de frente, o que tem impactos ainda mais graves no cenário caótico da pandemia. Seguindo a tendência de outros países, como Itália ${ }^{6}$ e Estados Unidos $^{7}$, para aumentar a disponibilidade de profissionais da área da saúde envolvidos diretamente no atendimento durante a pandemia, o Ministério da Educação publicou, em 9 de abril de 2020, a Portaria no 383 que autorizou a antecipação da formatura para estudantes de várias áreas da saúde, incluindo Medicina $^{8}$. Na cidade de Curitiba, quatro faculdades de Medicina aderiram à portaria, tendo os acadêmicos cumprido mais de $75 \%$ da carga horária dos estágios obrigatórios.

Nesse sentido, os efeitos da antecipação da formatura em um contexto de crise na saúde mundial, do ponto de vista emocional, merecem ser avaliados. De acordo com Unadkat et al. ${ }^{9}$, a pandemia de Covid-19 pode elevar a pressão sobre os profissionais de saúde, já que o aumento da demanda de trabalho é significativo. Segundo Flotte et al. ${ }^{7}$, a antecipação em dois meses da colação de grau da Universidade Médica de Massachusetts levou novos médicos a se envolver em uma variedade de respostas à pandemia de Covid-19, contribuindo para diminuir a carga de trabalho para residentes e professores médicos ${ }^{7}$.

O objetivo do presente artigo, dessa maneira, é realizar uma primeira avaliação, ainda preliminar, do impacto da antecipação da graduação para os formandos de Medicina durante a pandemia de Covid-19.

\section{MÉTODOS}

Trata-se de estudo observacional e transversal realizado por meio da aplicação de questionário com 13 perguntas: em cinco delas, utilizou-se a escala Likert de avaliação; em seis, adotou-se o formato múltipla escolha; e duas foram descritivas. Enviou-se o questionário por meio do Formulário Google, e o estudo foi aprovado pelo Comitê de Ética do Setor de Ciências da Saúde da Universidade Federal do Paraná (UFPR) em 27 de agosto de 2020: Certificado de Apresentação para Apreciação Ética (CAAE) n³4840820.9.0000.0102.

Os questionários foram aplicados em alunos de Medicina, das universidades de Curitiba, no Paraná, formados no primeiro semestre de 2020, que anteciparam a outorga de grau em razão da pandemia de Covid-19.

Tabularam-se os dados coletados em planilha do Excel, em que se calcularam as medidas de tendência e dispersão, e geraram-se os gráficos de setores.

\section{RESULTADOS}

Ao todo, 113 formandos responderam ao questionário. Quanto às características dos participantes, 72 entrevistados eram do sexo feminino $(63,7 \%)$ e 41 do sexo masculino $(36,3 \%)$. As informações quanto à idade encontram-se representadas na Tabela 1.

Sobre a instituição na qual completou a graduação (Gráfico 1), a maioria dos entrevistados era UFPR, seguida da Pontifícia Universidade Católica do Paraná (PUCPR).

Tabela 1. Informações quanto à idade dos participantes.

\begin{tabular}{cccc}
\hline Idade & Média & $\begin{array}{c}\text { Mínimo- } \\
\text { máximo }\end{array}$ & $\begin{array}{c}\text { Desvio } \\
\text { padrão }\end{array}$ \\
\hline Feminino & 25,62 & $23-32$ & 1,74 \\
Masculino & 26,58 & $23-41$ & 3,28 \\
\hline Total & 25,97 & $23-41$ & 2,44 \\
\hline
\end{tabular}

Idade expressa em anos. 
Gráfico 1.Universidades onde os participantes completaram a graduação.

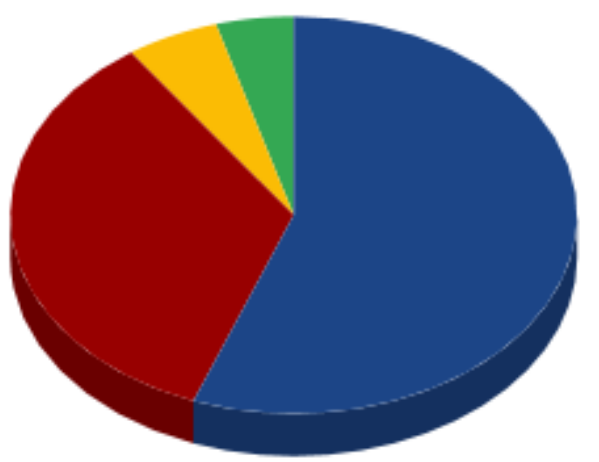

Fempar $=$ Faculdade Evangélica Mackenzie do Paraná; FPP = Faculdades Pequeno Príncipe; PUCPR = Pontifícia Universidade Católica do Paraná; UFPR $=$ Universidade Federal do Paraná.

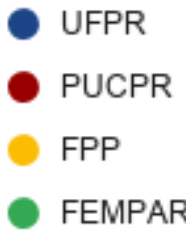

Gráfico 2.Estágios não cursados ou cursados apenas parcialmente.

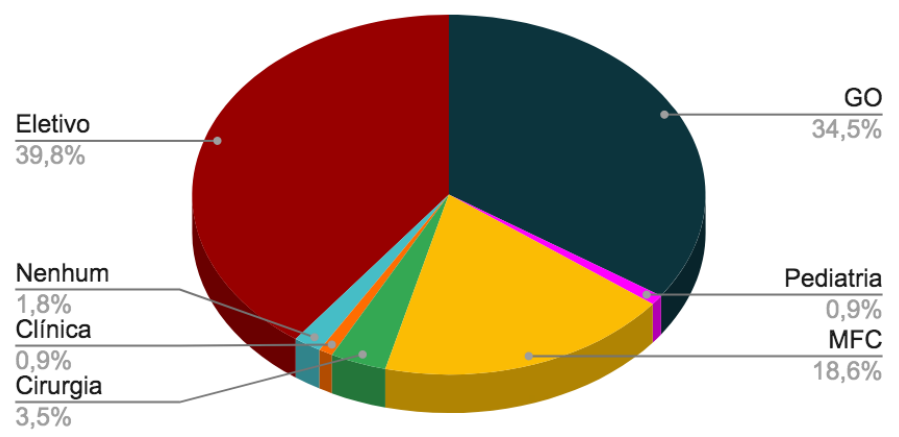

GO = ginecologia e obstetrícia; MFC = medicina de família e comunidade.

Gráfico 3. Respostas dos participantes a diferentes perguntas.

2,7

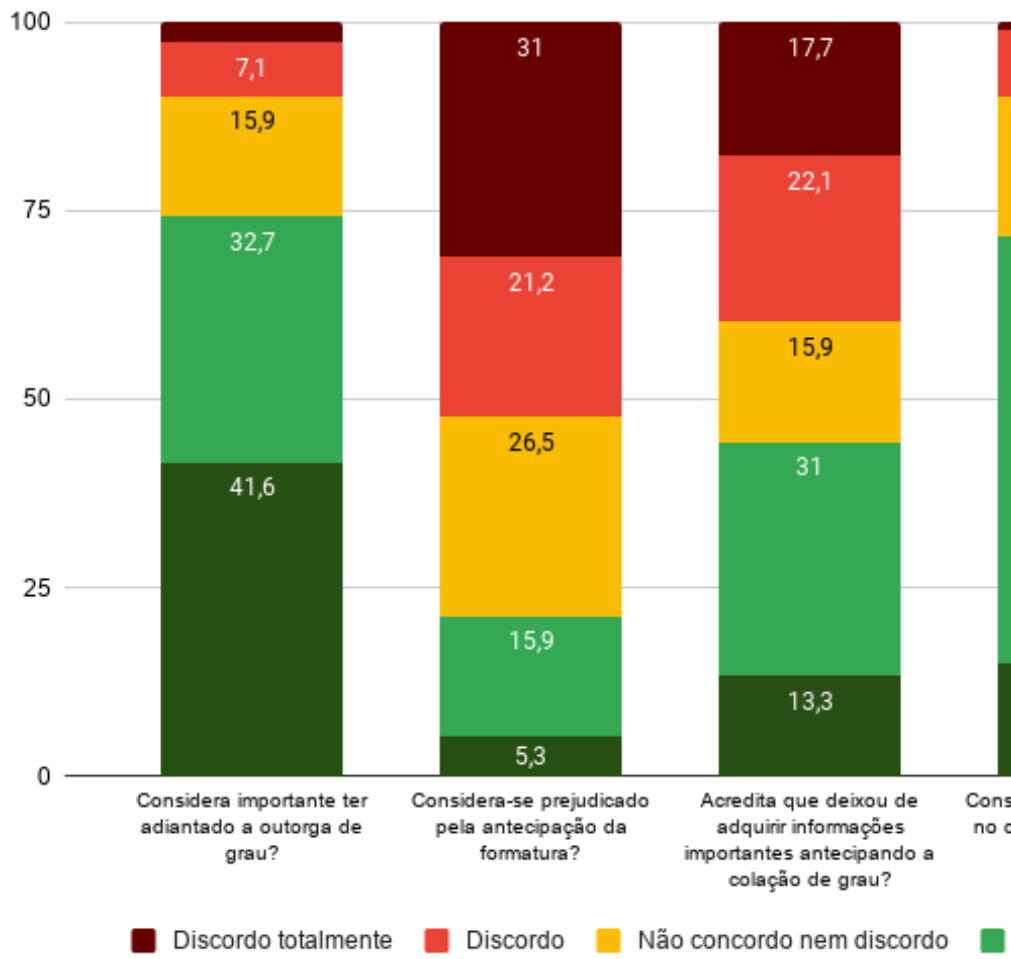

0,9

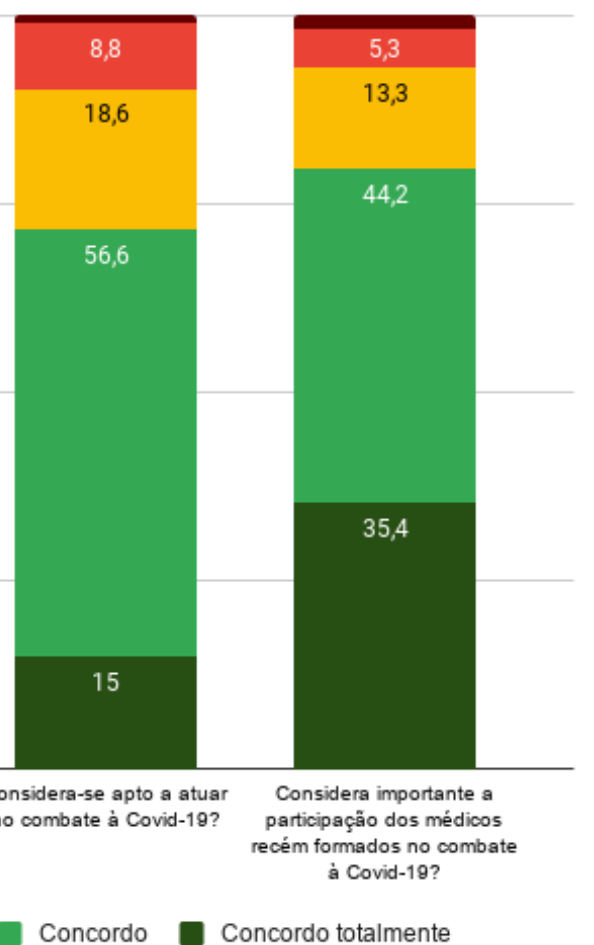

Eixo X em porcentagem. Os números nas colunas representam as porcentagens calculadas.

Quanto aos estágios não cursados (ou cursados parcialmente) em decorrência da antecipação da formatura, a maioria dos entrevistados indicou o eletivo e o de medicina de família e comunidade (Gráfico 2).

Em relação à atuação profissional, 101 participantes relataram que estão atuando como médicos (89,4\%). Entre estes, $64(63,36 \%)$ afirmaram que estão trabalhando diretamente no atendimento de casos de Covid-19. Entre os 37 restantes, 27 (72,97\%), embora não estejam atuando diretamente, relataram atuação indireta na pandemia (trabalho em locais que não focam o atendimento à Covid-19, mas que recebem alguns casos).

Quanto ao local de trabalho, $86,13 \%$ estão atuando no estado do Paraná, sendo 54 (53,5\%) em Curitiba e na região metropolitana. Em seguida, aparece o estado de Santa Catarina com nove respostas (8,91\%). Outras respostas foram: Mato Grosso (duas), São Paulo (duas) e Rio Grande do Norte (uma).

A respeito da importância da antecipação da outorga de grau, a maioria dos participantes concorda totalmente ou concorda, e apenas três (2,65\%) discordam totalmente (Gráfico 3).

Quanto ao fato de o participante se sentir prejudicado 
pela antecipação da formatura, mais da metade dos entrevistados discordam ou discordam completamente (Gráfico 3). Contudo, 43,3\% acreditam que deixaram de adquirir informações importantes em sua formação ao anteciparem a colação de grau (Gráfico 3).

Por fim, quanto ao fato de trabalharem na pandemia, $79,6 \%$ consideram importante a atuação de médicos recémformados no combate à Covid-19 (Gráfico 3). Ainda nesse sentido, a maioria dos entrevistados considera-se apta para atuar na pandemia (Gráfico 3).

\section{DISCUSSÃO}

No início de abril de 2020, em meio à intensificação da pandemia de Covid-19 no Brasil, foi publicada pelo Ministério da Educação a Portaria no 374 que autorizava as instituições de ensino a, antecipar, em caráter excepcional, a colação de grau dos alunos regularmente matriculados no último período dos cursos de Medicina, Enfermagem, Farmácia e Fisioterapia, desde que completados $75 \%$ da carga horária prevista para o período de internato médico ou estágio supervisionado ${ }^{10}$.

Inicialmente, os formandos deveriam colar grau para que pudessem atuar exclusivamente nas ações de combate à pandemia do novo coronavírus - Covid-19. Em 13 de abril, contudo, foi publicada uma nova portaria no Diário Oficial da União que revogou a Portaria n 374 e a necessidade de atuação exclusiva na pandemia após a colação de grau ${ }^{8}$. Nesse sentido, é interessante destacar o que foi observado em nossa pesquisa: mesmo sem haver tal obrigatoriedade, os participantes, em sua maioria, estão, sim, atuando como médicos e trabalhando direta ou indiretamente no combate à pandemia. Nesse contexto, os participantes foram questionados sobre a importância do adiantamento da outorga de grau, e $72,3 \%$ dos formandos concordaram ou concordaram totalmente com tal afirmativa. Isso possivelmente mostra que os novos médicos consideram importante atuação médica deles em meio à pandemia.

Ainda sobre a atuação, evidencia-se que, majoritariamente, os formandos estão atuando no estado do Paraná, especialmente em Curitiba e na região metropolitana. Isso corrobora a importância local e regional que esses novos profissionais tiveram, ajudando a suprir a necessidade criada pela pandemia. Para exemplificar, somente em Curitiba, até o dia 13 de novembro de 2020, foram registrados 58.633 casos, sendo 1.553 óbitos. Na cidade, o pico de casos ativos ocorreu no final de julho. Em âmbito estadual, já são 225.514 casos confirmados ${ }^{11}$.

Além do aumento da demanda, outro ponto a ser destacado para a necessidade e importância de novos profissionais refere-se à contaminação e ao afastamento temporário de muitos profissionais de saúde. A Organização Pan-Americana da Saúde (Opas) estima que, até setembro de
2020, cerca de 570 mil profissionais de saúde já haviam sido infectados, sendo registrados 2,5 mil óbitos em decorrência da Covid-19 nas Américas ${ }^{12}$.

Muito foi debatido sobre a capacitação e se esses profissionais estariam prontos para enfrentar a pandemia. Oliveira et al. ${ }^{13}$ indagam, em artigo publicado em abril de 2020, se houve um avanço satisfatório na formação dos médicos, de modo a torná-los aptos a atender às necessidades de saúde da população no momento que vivemos. O curso de Medicina tem, no mínimo, 7.200 horas, com currículos que passam de oito mil horas, como da UFPR ${ }^{14}$. Com a antecipação da formatura, apenas $5 \%$ da carga horária total do curso (25\% da carga horária do estágio) deixou de ser cumprida, e todo o conteúdo teórico-prático essencial para a formação médica foi finalizado. Isso se reflete na resposta dos formandos sobre se sentirem prejudicados com a antecipação da formatura, em que 52,2\% discordaram totalmente ou discordaram dessa afirmação.

Pode-se também expor que 39,8\% deixaram de cursar o estágio eletivo, sendo essa modalidade uma escolha do acadêmico pela área de seu interesse, já tendo cursado todos os estágios obrigatórios. Quando analisamos a grande área obrigatória que deixou de ser cursada, temos 34,5\% dos entrevistados respondendo ginecologia e obstetrícia, disciplina abordada em outros estágios do currículo, como em medicina da família e comunidade ou na maternidade, já realizados anteriormente por esses formandos, o que favorece a resposta positiva quanto ao não prejuízo com a antecipação.

A maior parte, $71 \%$ dos formandos entrevistados, referiu estar apta a atuar no combate à Covid-19. Isso pode ser explicado, além das extensas horas de preparação no curso de Medicina, pelo fato de se tratar de uma doença nova com constantes mudanças de protocolos de manejo. A pandemia trouxe um cenário inédito no qual profissionais mais experientes também tiveram que aprender com os recém-formados, os quais, por ainda estarem em fase de formação, têm maior capacidade de assimilação e aceitação de novos conceitos, o que poderia ser considerado uma vantagem.

No futuro, talvez um enfoque maior no preparo e suporte psicológico para alunos de Medicina em situações de pandemia fosse mais impactante do que somente o conhecimento de bases fisiopatológicas e tratamento de doenças ${ }^{15}$.

Como bem observado por Gallagher e Schleyer ${ }^{16}$, em artigo recente que trata da insegurança e do medo de estudantes e recém-formados ante a pandemia da Covid-19, vê-los dispostos a atuar no enfrentamento de uma doença tão grave e tão contagiosa nos dá a esperança de que o futuro da medicina está em boas mãos.

Quanto às limitações, destaca-se que nosso estudo foi realizado apenas em uma cidade e englobou majoritariamente 
alunos de apenas duas instituições. É também importante destacar que realizamos um estudo do tipo transversal, conduzido poucos meses após a graduação. Sabemos que o acompanhamento de longo prazo dos participantes poderá elucidar melhor certas questões e gerar resultados mais objetivos na avaliação do impacto.

\section{CONCLUSÃO}

O presente estudo contribui para mostrar que a antecipação da colação de grau foi bem-sucedida no seu objetivo de aumentar a disponibilidade de profissionais da área da saúde envolvidos diretamente no atendimento à pandemia. Além disso, a pesquisa permitiu também avaliar a opinião dos estudantes graduados antecipadamente, os quais foram os principais afetados pela medida, mas que, de acordo com nossa pesquisa, mostraram opinião favorável quanto à antecipação.

\section{CONTRIBUIÇÃO DOS AUTORES}

Paula Adamo de Almeida participou da concepção do trabalho, da aquisição dos dados, da redação do artigo e da revisão crítica do conteúdo intelectual. Viktoria Weihermann participou da aquisição, análise e interpretação dos dados, da redação do artigo e da revisão crítica do conteúdo intelectual. Silvania Klug Pimentel participou da concepção do trabalho, da redação do artigo e da revisão crítica do conteúdo intelectual. Gustavo Lenci Marques. Camila Girardi Fachin e Ipojucan Calixto Fraiz participaram da redação do artigo e da revisão crítica do conteúdo intelectual.

\section{CONFLITO DE INTERESSES}

Os autores declaram não haver conflito de interesses neste estudo.

\section{FINANCIAMENTO}

Declaramos que não houve financiamento para a realização desta pesquisa.

\section{REFERENCIAS}

1. Cascella M, Rajnik M, Cuomo A, Dulebohn SC, Di Napoli R. Features, evaluation and treatment coronavirus (Covid-19). In Statpearls. 2020 Mar 8. StatPearls Publishing

2. Velavan TP, Meyer CG. The COVID-19 epidemic. Trop Med Int health. 2020;25(3):278.

3. Zhou F, Yu T, Du R, Fan G, Liu Y, Liu Z, et al. Clinical course and risk factors for mortality of adult inpatients with Covid-19 in Wuhan, China: a retrospective cohort study. The Lancet. 2020;395(10229):1038.

4. Tian S, Hu N, Lou J, Chen K, Kang X, Xiang Z, et al. Characteristics of Covid-19 infection in Beijing. J Infec. 2020;80(4):401-6.

5. Wang $B, L i R, L u Z$, Huang Y. Does comorbidity increase the risk of patients with Covid-19: evidence from meta-analysis. Aging (Albany NY). 2020 Apr 15;12(7):6049.

6. Itália antecipa formatura de estudantes de medicina para combater Covid-19. Comunità Italiana; 18 mar 2020 [access in 6 jul 2020]. Available from https://comunitaitaliana.com/italia-antecipa-formatura-de-estudantes-demedicina-para-combater-covid-19/.

7. Flotte TR, Larkin AC, Fischer MA, Chimienti SN, DeMarco DM, Fan PY, et al. Accelerated graduation and the deployment of new physicians during the Covid-19 pandemic. Acad Med. 2020;95(10):1492-4.

8. Brasil. Portaria $n^{\circ} 383$, de 9 de abril de 2020. Dispõe sobre a antecipação da colação de grau para os alunos dos cursos de Medicina, Enfermagem, Farmácia e Fisioterapia, como ação de combate à pandemia do novo coronavírus - Covid-19. Diário Oficial da União; 13 abr 2020. Seção 1.

9. Unadkat S, Farquhar M. Doctors' wellbeing: self-care during the Covid-19 pandemic. BMJ. 2020 Mar 24;368:m1150.

10. Brasil. Portaria $n^{\circ} 374$, de 3 de abril de 2020. Dispõe sobre a antecipação da colação de grau para os alunos dos cursos de Medicina, Enfermagem, Farmácia e Fisioterapia, exclusivamente para atuação nas ações de combate à pandemia do novo coronavírus - Covid-19. Diário Oficial da União; 6 abr. 2020. Seção 1, p. 66.

11. Curitiba. Monitoramento Covid-19. Dados obtidos em 12/11/2020 [access in 18 nov 2020]. Available from: https://mid.curitiba.pr.gov.br/conteudos/ coronavirus/PAINEL_COVID_CTBA_13112020.pdf.

12. Organização Pan-Americana da Saúde. Cerca de 570 mil profissionais de saúde se infectaram e 2,5 mil morreram por Covid-19 nas Américas [access in 18 nov 2020]. Available from: https://www.paho.org/bra/index. php?option $=$ com_content $\&$ view $=$ article $\& i d=6270:$ cerca-de- $570-\mathrm{mil}-$ profissionais-de-saude-se-infectaram-e-2-5-mil-morreram-por-covid-19nas-americas\&ltemid $=812$.

13. de Oliveira SS, Postal EA, Afonso DH. As escolas médicas e os desafios da formação médica diante da epidemia brasileira da Covid-19: das (in)certezas acadêmicas ao compromisso social. APS em Revista. 2020;2(1):56-60.

14. Conselho de Ensino, Pesquisa e Extensão da Universidade Federal do Paraná Resolução no 44/2018. Fixa currículo pleno do curso de Medicina, do Setor de Ciências da Saúde, da Universidade Federal do Paraná. 21 set 2020.

15. O'Byrne L, Gavin B, McNicholas F. Medical students and Covid-19: the need for pandemic preparedness. J Med Ethics. 2020 Sep 10;46(9):623-6.

16. Gallagher TH, Schleyer AM. “We Signed Up for This!" - student and trainee responses to the Covid-19 pandemic. N Engl J Med. 2020;382(25):e96. 